\title{
A case report and literature review: previously excluded tuberculosis masked by amiodarone induced lung injury
}

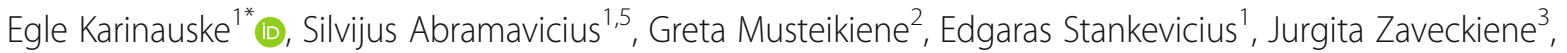
Vidas Pilvinis $^{4}$ and Edmundas Kadusevicius ${ }^{1}$

\begin{abstract}
Background: Amiodarone is an antiarrhythmic drug which is used to treat and prevent several dysrhythmias. This includes ventricular tachycardia and fibrillation, wide complex tachycardia, as well as atrial fibrillation (AF) and paroxysmal supraventricular tachycardia. Amiodarone may prove to be the agent of choice where the patient is hemodynamically unstable and unsuitable for direct current (DC) cardioversion. Although, it is not recommended for long-term use. The physician might encounter issues when differentiating amiodarone-induced lung toxicity with suspicion of interstitial lung disease, cancer or vasculitis. Adverse drug reactions are difficult to confirm and it leads to serious problems of pharmacotherapy.
\end{abstract}

Case presentation: A 78-year-old Caucasian male pensioner complaining of fever, dyspnea, malaise, non-productive cough, fatigue, weight loss, diagnosed with acute respiratory failure with a 16-year long history of amiodarone use and histologically confirmed temporal arteritis with long-term glucocorticosteroid (GCC) therapy.

Patient was treated for temporal arteritis with GCC for $\sim 1$ year, then fever and dyspnea occurred, and the patient was hospitalized for treatment of bilateral pneumonia. Chest X-ray and chest high resolution computed tomography (HRCT) indicated several possible diagnoses: drug-induced interstitial lung disease, autoimmune interstitial lung disease, previously excluded pulmonary TB. Amiodarone was discontinued. Antibiotic therapy for bilateral pneumonia was started. Fiberoptic bronchoscopy with bronchial washings and brushings was performed. Acid fast bacilli (AFB) were found on Ziehl-Nielsen microscopy and tuberculosis (TB) was confirmed (later confirmed to be Mycobacterium tuberculosis in culture), initial treatment for TB was started. After a few months of treating for TB, patient was diagnosed with pneumonia and sepsis, empiric antibiotic therapy was prescribed.

After reevaluation and M. Tuberculosis identification, the patient was referred to the Tuberculosis hospital for further treatment. After 6 months of TB treatment, pneumonia occurred which was complicated by sepsis. Despite the treatment, multiple organ dysfunction syndrome evolved and patient died. Probable cause of death: pneumonia and sepsis.

Conclusions: The current clinical case emphasizes issues that a physician may encounter in the differential diagnostics of amiodarone-induced lung toxicity with other lung diseases.

Keywords: Clinical pharmacology, Amiodarone induced pulmonary toxicity, Atrial fibrillation, Adverse drug reaction, Polypharmacy

\footnotetext{
*Correspondence: egle.zlatkute@gmail.com

${ }^{1}$ Institute of Physiology and Pharmacology, Lithuanian University of Health

Sciences, A. Mickeviciaus str. 9, 44307 Kaunas, LT, Lithuania

Full list of author information is available at the end of the article
}

(c) The Author(s). 2018 Open Access This article is distributed under the terms of the Creative Commons Attribution 4.0 International License (http://creativecommons.org/licenses/by/4.0/), which permits unrestricted use, distribution, and reproduction in any medium, provided you give appropriate credit to the original author(s) and the source, provide a link to the Creative Commons license, and indicate if changes were made. The Creative Commons Public Domain Dedication waiver (http://creativecommons.org/publicdomain/zero/1.0/) applies to the data made available in this article, unless otherwise stated. 


\section{Background}

Amiodarone is an antiarrhythmic drug which is used to treat and prevent several dysrhythmias. This includes ventricular tachycardia and fibrillation, wide complex tachycardia, as well as atrial fibrillation (AF) and paroxysmal supraventricular tachycardia. Amiodarone may prove be to the agent of choice where the patient is hemodynamically unstable and unsuitable for direct current (DC) cardioversion. It is recommended in such a role by the UK government's National Institute for Health and Clinical Excellence (NICE) [1] and American College of Cardiology, American Heart Association and Heart Rhythm Society [2]. Although, it is not recommended for long-term use. One of amiodarone adverse events is drug-induced respiratory disease (DIRD) which is rare and can be subdivided into drug induced pulmonary parenchymal disease [3] and drug-induced interstitial lung disease (DILD) [4]. DILD may present when using amiodarone and other medicines, such as angiotensin converting enzyme inhibitors (ACEi), angiotensin receptor blockers (ARB), anticoagulants, aspirin, beta blockers (BB) etc. [5]. Patients with DILD can present with a number of symptoms, such as progressive shortness of breath (dyspnea), non-productive cough, malaise, fever, pleuritic chest pain (Table 1), and it is important to ascertain the duration, severity, and progression of symptoms. Chest X-ray may show radiological abnormalities, such as reticular, nodular or mixed patterns [6]. The images of the chest high-resolution computed tomography (HRCT) usually contain nonspecific findings including patchy, scattered or diffuse ground-glass opacities, consolidation, irregular reticular opacities and fibrosis (traction bronchiectasis, honeycombing) [7].
The chest HRCT provides greater diagnostic accuracy than the plain chest radiograph and helps to narrow the differential diagnosis of interstitial lung disease (ILD). For example, bilateral symmetric hilar adenopathy and upper lung zone reticular opacities suggest sarcoidosis or another granulomatous disease; or in an asymptomatic patient, diffuse, calcified, nodular, interstitial opacities may reflect healed varicella-zoster pneumonia [8].

Histologically DILD may be identified as interstitial pneumonia (an inflammation of the lung interstitium, such as alveolar septa), hypersensitivity pneumonitis (the interstitial space is infiltrated by lymphocytes and plasma cells), bronchiolitis obliterans, organizing pneumonia and other [9]. Amiodarone acts via cytotoxic $\mathrm{T}$ cells and immunological reaction resulting in a diffuse interstitial pneumonitis with fibrosis and 'ground-glass' opacities in chest HRCT [10].

It is important to keep in mind the other possible pulmonary diseases to differentiate properly. One of them is tuberculosis (TB) which remains an important health problem in Lithuania with $\sim 41.89$ new $\mathrm{TB}$ cases per 100,000 population (2015) [11]. Thus, the specificity of BACTEC is 99\% [12], there are cases when TB is not diagnosed because of low concentration of bacteria in the sputum or bronchial washings. The other important differential diagnosis are ILD which might look very similar to DILD on HRCT scans, vasculitis, Wegener's granulomatosis, lung cancer and other bacterial infections.

We present a case of acute respiratory failure, with previously excluded TB (based on negative bacteriological testing for TB), amiodarone use (16 years 400 $\mathrm{mg} /$ daily) and histologically confirmed temporal vasculitis with suspected exacerbation. In accordance with

Table 1 Possible differential diagnosis of lung diseases in the current case history

\begin{tabular}{|c|c|c|}
\hline Possible diagnosis & Clinical symptoms & Radiological findings \\
\hline Interstitial lung disease & $\begin{array}{l}\text { Dyspnea, non-productive cough, malaise, fatigue, } \\
\text { weight loss }\end{array}$ & $\begin{array}{l}\text { X-ray - consolidation, fibrosis; HRCT - consolidation, fibrosis, ground glass } \\
\text { partial alveolar filing, reticulonodular pattern. }\end{array}$ \\
\hline Tuberculosis & $\begin{array}{l}\text { Productive cough, malaise, fatigue, weight loss, } \\
\text { night sweats, hemoptysis }\end{array}$ & $\begin{array}{l}\text { X-ray - infiltration, cavitation, nodularity, hilar/paratracheal } \\
\text { lymphadenopathy, pleural effusion, atelectasis; HRCT - infiltration, } \\
\text { granulomas and tree-in-bud appearance }\end{array}$ \\
\hline $\begin{array}{l}\text { Amiodarone-induced } \\
\text { interstitial lung disease }\end{array}$ & $\begin{array}{l}\text { Progressive shortness of breath (dyspnea), non- } \\
\text { productive cough, malaise, fever, pleuritic chest } \\
\text { pain }\end{array}$ & $\begin{array}{l}\text { X-ray - consolidation, fibrosis; HRCT - diffuse interstitial pneumonitis with } \\
\text { fibrosis and 'ground-glass' opacities, consolidation }\end{array}$ \\
\hline Vasculitis & $\begin{array}{l}\text { Fever, weight-loss, fatigue, evidence of multisys- } \\
\text { tem involvement, rashes }\end{array}$ & $\begin{array}{l}\text { X-ray - pneumonia-like x-ray picture; } \mathrm{HRCT} \text { - bilateral perihilar or periph- } \\
\text { eral ground-glass opacities, pulmonary haemorrhage }\end{array}$ \\
\hline $\begin{array}{l}\text { Wegener's } \\
\text { granulomatosis }\end{array}$ & $\begin{array}{l}\text { Necrotizing granulomatous lesions of respiratory } \\
\text { tract, ulcers, malaise, fatigue, weight loss }\end{array}$ & $\begin{array}{l}\text { HRCT - perihilar or peripherical ground-glass opacities, pulmonary haem- } \\
\text { orrhage, necrotizing granulomas }\end{array}$ \\
\hline Lung tumor & $\begin{array}{l}\text { Dyspnea, non-productive cough, malaise, fatigue, } \\
\text { weight loss, hemoptysis }\end{array}$ & $\begin{array}{l}\text { X-ray - nodule or mass with hilar enlargement, lobulated hilar mass, } \\
\text { atelectasis; HRCT - solid or mixed pulmonary nodules or mass, atelectasis, } \\
\text { lymphadenopathy }\end{array}$ \\
\hline $\begin{array}{l}\text { Bacterial lung } \\
\text { infections }\end{array}$ & $\begin{array}{l}\text { Fever, chills, productive cough, dyspnea, pleuritic } \\
\text { chest pain, fatigue }\end{array}$ & $\begin{array}{l}\text { X-ray - consolidation of the lobe, dense opacities, pneumothorax, } \\
\text { hydrothorax; HRCT - centrilobular nodules, tree-in-bud pattern, pleural- } \\
\text { based consolidation }\end{array}$ \\
\hline
\end{tabular}


patient history and the radiological findings the differential diagnosis in this case included the drug-induced pulmonary toxicity, autoimmune lung injury, TB and other lung diseases suitable to this case.

\section{Case presentation}

A 78-year-old Caucasian male was diagnosed with temporal arteritis based on clinical presentation and biopsy of temporal artery showing granulomatous inflammation. The chest HRCT revealed pulmonary changes similar to autoimmune ILD. Based on radiological findings, the diagnosis of pulmonary TB was considered but sputum smears and microscopy of bronchial washings were negative and this diagnosis was rejected. Thus, the treatment with methylprednisolone $(8 \mathrm{mg} /$ daily) for temporal arteritis was initiated more than a half-a-year ago. At the time, patient was using amiodarone tablets $400 \mathrm{mg} /$ daily for recurrent atrial fibrillation (AF) in 2002.

Patient arrived at the rheumatology outpatient department, complaining of fever and dyspnea, his parameters of central hemodynamics were normal, ECG showed sinus rhythm, C-reactive protein (CRP) was $118 \mathrm{mg} / \mathrm{l}$. The diagnosis of bilateral pneumonia, consistent with pulmonary vasculitis, was established with chest X-ray, and patient was admitted to the rheumatology department. Empiric antibiotic therapy with cefuroxime ( $4.5 \mathrm{~g} /$ daily) and methylprednisolone ( $32 \mathrm{mg} /$ daily) for suspected exacerbation of vasculitis were prescribed.

On the third day of hospitalization, patient complained of malaise, pressure and tightness in his chest. ECG was performed and the AF was identified. The patient was transferred to the Intensive Care Unit (ICU) for direct current cardioversion into the sinus rhythm. Later the patient was successfully transferred back to the rheumatology department. After $24 \mathrm{~h}$, another episode of AF recurred. Electrolytes were within normal range. Pharmacological conversion was prescribed with $300 \mathrm{mg}$ amiodarone IV solution. Despite the pharmacological management of the AF, patient presented with severe dyspnea, tachypnea with signs respiratory insufficiency. The multidisciplinary consult concluded that the patient suffers either from autoimmune interstitial lung disease or drug induced lung injury. In addition, there was little evidence to exclude bacterial infection. Thus, it was decided to discontinue amiodarone therapy, initiate corticosteroid therapy, and repeat bronchoscopy, take sputum smears and bronchial washings for bacterial diagnostics and chest HRCT. The chest HRCT identified pulmonary emphysema, thickening of intra- and interlobular septa, with random distribution nodules, ground-glass opacities, fibrosis and traction bronchiectasis, progression of mediastinal lymphadenopathy (Figs. 1a, 2a and 3a). Fiberoptic bronchoscopy with bronchial washings and brushings was performed. Acid fast bacilli (AFB) were found on Ziehl-Nielsen microscopy. The diagnosis of TB was confirmed and the anti-TB therapy was initiated with isoniazid $(300 \mathrm{mg} /$ day), rifampicine $(600 \mathrm{mg} /$ day), ethambutol $(1200 \mathrm{mg} /$ day $)$ and pyrazinamide $(2000 \mathrm{mg} /$ day). Control chest HRCT was performed after four months of TB treatment. Signs described on earlier chest HRCT regressed - nodules became more restricted with thinning of intra- and interlobular septa shown (Figs. $1 \mathrm{~b}, 2 \mathrm{~b}$ and $3 \mathrm{~b}$ ). However, the patient developed pneumonia. Blood culture did not confirm bacterial growth, but sepsis was diagnosed clinically. Empiric antibiotic therapy was prescribed. Despite the treatment, multiple organ dysfunction syndrome evolved and patient died. The lung biopsy was not performed thus it is not possible to completely exclude amiodarone induced interstitial lung disease accompanying pulmonary TB.

\section{Discussion}

The current clinical case shows that there are many possible lung diseases that should be taken into consideration when looking for the cause of acute respiratory failure (Table 1). DILD may evolve if untreated as a typically

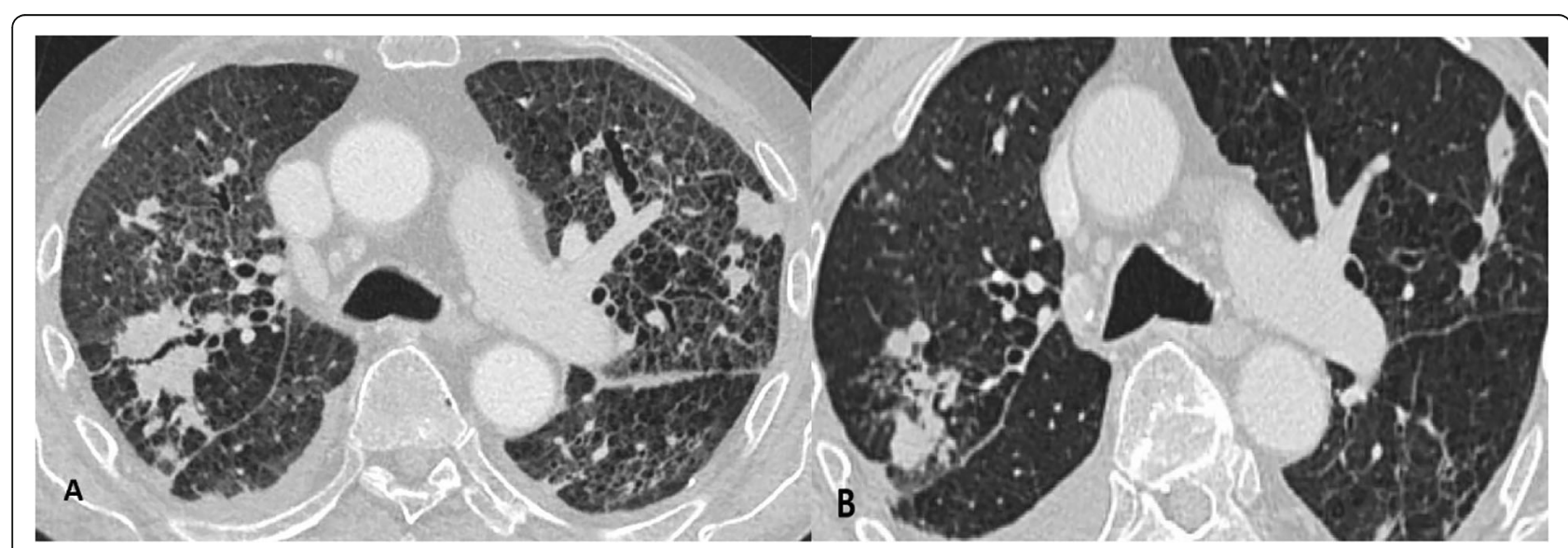

Fig. 1 Axial reconstruction of chest HRCT before (a) and after (b) the treatment 


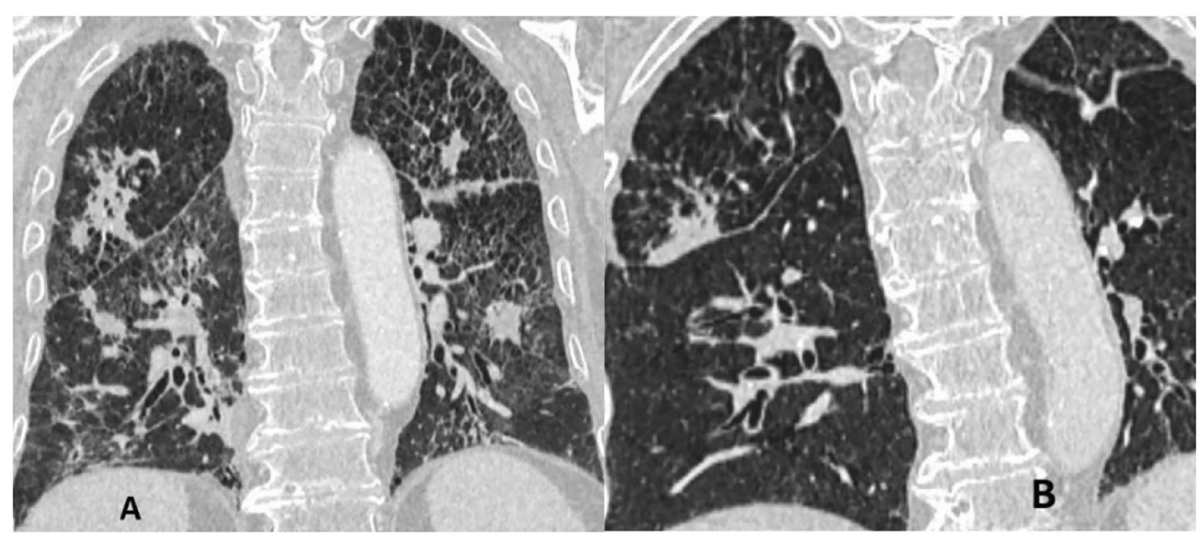

Fig. 2 Coronal reconstruction of chest HRCT before (a) and after (b) the treatment

nonnecrotising granulomatous lung disease, hilar or mediastinal lymphadenopathy may be present on chest HRCT [13]. Depending on the immune status of patients, special stains and molecular analyses are necessary to differentiate DILD from mycobacterial or other infections. A lot of drugs (methotrexate, interferon, amiodarone, infliximab, etanercept, leflunomide, mesalamine and sirolimus) can be causative of granulomas in drug-induced respiratory diseases [14]. The current patients' chest HRCT showed signs suitable to drug-induced ILD (Figs. 1a, 2a and 3a). Amiodarone pulmonary toxicity should be taken into consideration, especially in elderly patients with respiratory symptoms and pulmonary changes, even if only a low dose of amiodarone is administered over a longer time period [15]. The current patient was using amiodarone for $\mathrm{AF}$ at least for 16 years $400 \mathrm{mg} /$ daily. It is known that amiodarone tends to accumulate in fatty tissues and its elimination half-life is 25 to 100 days, pulmonary toxicity may initially progress despite drug discontinuation and may recur upon steroid withdrawal [16]. In addition, the diagnosis of TB does not exclude the possibility of accompanying amiodarone toxicity. The correct way to exclude drug-induced ILD is to perform an open lung biopsy (OLB), however, these findings are not always pathognomonic for drug toxicity and correlation with clinical, laboratory, and radiologic data is required. Thus OLB may aid the exclusion of underlying autoimmune disease or infection and document the pattern of lung injury. Another approach is to perform the transbronchial biopsy, but it has more limitations because the lung tissue obtained is very small and may be non-specific [17]. It was found that HRCT performed without intravenous contrast shows increased density in parenchymal organs, such as lungs and liver, when using amiodarone [18]. So the TB and autoimmune ILD were other of many possible explanations based on clinical grounds and patient's history. The diagnosis of TB was considered because of the frequency of this illness in Lithuania and findings on chest HRCT. There were only nonspecific clinical signs, such as prolonged cough, lymphadenopathy, fever, night sweats and

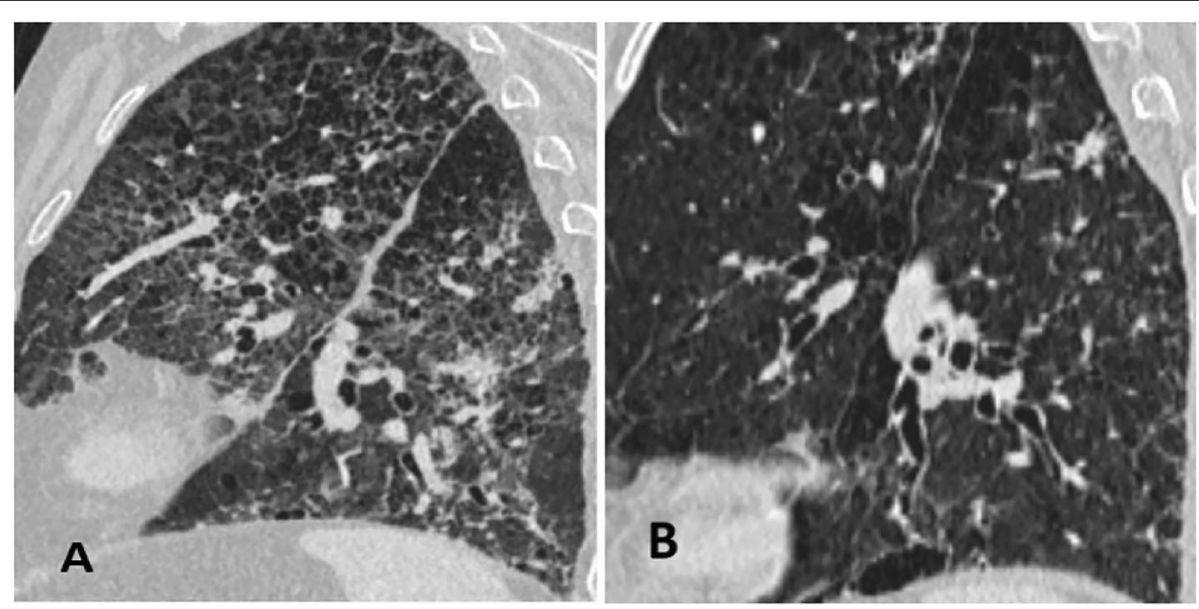

Fig. 3 Sagittal reconstruction of chest HRCT before (a) and after (b) the treatment 
weight loss, without typical radiological findings for TB like focal infiltration of the upper lobe(s), cavitation, tissue destruction, and fibrosis with traction bronchiectasis, enlargement of hilar/mediastinal lymph nodes, small nodular lesions and pleural effusions [19]. In the current case radiological findings did not show any specific TB changes (Figs. 1a, 2a and 3a). It should be considered that TB may also present with nonnecrotising granulomas on chest HRCT, depending on the immune status of the patient [13]. Immunosuppressive treatment may cause complications, such as bacterial infections. In the current case the patient suffered from pneumonia which was complicated by sepsis with multiple organ dysfunction syndrome. It might be related to autoimmune temporal arteritis and its treatment with GCCs. Also, the exacerbation of temporal arteritis can cause ILD which was taken into account because of already existing diagnosis - temporal arteritis which was confirmed from the biopsy of temporal artery. Radiological findings can also show nonnecrotising granulomas which is a non-specific sign. Lung biopsy can help to exclude other possible lung injuries and confirm autoimmune processes in lungs.

\section{Conclusions}

The current clinical case emphasizes issues which may be encountered by a physician differentiating amiodarone-induced lung toxicity with suspicion of interstitial lung disease or other lung diseases, like cancer or vasculitis. Firstly, amiodarone may cause non-necrotizing granulomatous changes in lungs when it is used $400 \mathrm{mg} /$ daily or more for a prolonged period, as it was seen in the current case. Secondly, Mycobacteria may have low concentration in bodily fluids and it might not be diagnosed using Ziehl-Nielsen microscopy for AFB. Thirdly, the autoimmune ILD might be suspected when the patient has a medical history of any other granulomatous disease, as in this case - temporal arteritis which was treated with GCCs or any other immunosuppressive agents which had an impact on patient's immune status and his susceptibility to bacterial infections.

\section{Abbreviations \\ ACEi: Angiotensin converting enzyme inhibitor; AF: Atrial fibrillation; AFB: Acid fast bacilli; BB: $\beta$ blockers; DILD: Drug-induced interstitial lung disease; DIRD: Drug-induced respiratory disease; \\ GCC: Glucocorticosteroids; HRCT: High resolution computed tomography; ICU: Intensive care unit; ILD: Interstitial lung disease; NICE: National Institute for Health and Clinical Excellence; OLB: Open lung biopsy; RF: Respiratory failure; TB: Tuberculosis}

\section{Acknowledgements}

Declared none.

Funding

No funding was necessary.

Availability of data and materials Not applicable.

\section{Authors' contributions}

EgK analyzed and interpreted the patient data regarding probable amiodarone induced pulmonary toxicity, SA analyzed and interpreted the patient data regarding probable amiodarone induced pulmonary toxicity, GM analyzed and interpreted the patient data regarding pulmonary tuberculosis and its treatment, ES analyzed and interpreted literature available, JZ analyzed and interpreted findings on patient's chest HRCT, VP analyzed and interpreted the patient data regarding the overall treatment of the patient, EdK analyzed and interpreted the patient data regarding probable amiodarone induced pulmonary toxicity. All authors participated in interpreting the data and revising the manuscript for important intellectual content. All authors approved the final version of the manuscript. No writing assistance was utilized in the production of this manuscript.

Ethics approval and consent to participate

Approval to analyze the case file was given by the patient (2018 01 06).

\section{Consent for publication}

Written consent to publish was obtained from the patient (2018 0106 ).

Patient was observed since his consent till his death.

\section{Competing interests}

The authors have no relevant affiliations or financial conflict with the subject matter or materials discussed in the manuscript.

\section{Publisher's Note}

Springer Nature remains neutral with regard to jurisdictional claims in published maps and institutional affiliations.

\section{Author details}

${ }^{1}$ Institute of Physiology and Pharmacology, Lithuanian University of Health Sciences, A. Mickeviciaus str. 9, 44307 Kaunas, LT, Lithuania. ${ }^{2}$ Department of Pulmonology, Medical Academy, Lithuanian University of Health Sciences Kaunas Clinics, Kaunas, Lithuania. ${ }^{3}$ Department of Radiology, Medical Academy, Lithuanian University of Health Sciences Kaunas Clinics, Kaunas, Lithuania. ${ }^{4}$ Department of Intensive Care, Medical Academy, Lithuanian University of Health Sciences Kaunas Clinics, Kaunas, Lithuania. ${ }^{5}$ Intensive care unit, Republican Vilnius University Hospital, Vilnius, Lithuania.

Received: 23 October 2018 Accepted: 12 December 2018

Published online: 29 December 2018

\section{References}

1. National Institute for Health and Care Excellence (2014) Atrial fibrillation: management [CG180]. Available at: https://www.nice.org.uk/guidance/cg180 (Accessed 5 Dec 2018).

2. Al-Khatib SM, Stevenson WG, Ackerman MJ, Bryant WJ, Callans DJ, Curtis AB, et al. AHA/ACC/HRS guideline for Management of Patients with Ventricular Arrhythmias and the prevention of sudden cardiac death. Circulation. 2017; 2018:138.

3. Prasad R, Gupta P, Singh A, Goel N. Drug induced pulmonary parenchymal disease. Drug Discov Ther. 2014;8(6):232-7.

4. Matsuno O. Drug-induced interstitial lung disease: mechanisms and best diagnostic approaches. Respir Res. 2012 May 31;13:39.

5. Kreuter M, Bonella F, Maher TM, et al. Effect of statins on diseaserelated outcomes in patients with idiopathic pulmonary fibrosis. Thorax. 2017;72:148.

6. Pipavath S, Godwin JD. Imaging of interstitial lung disease. Clin Chest Med. 2004;25:455.

7. Schwaiblmair M, Behr W, Haeckel T, Märkl B, Foerg W, Berghaus T. Drug induced interstitial lung disease. Open Respir Med J. 2012;6:63-74.

8. Sumikawa H, Johkoh T, Ichikado K, et al. Usual interstitial pneumonia and chronic idiopathic interstitial pneumonia: analysis of CT appearance in 92 patients. Radiology. 2006;241:258

9. Leslie KO. My approach to interstitial lung disease using clinical, radiological and histopathological patterns. J Clin Pathol. 2009;62(5):387-401.

10. Sweidan AJ, Singh NK, Dang N, Lam V, Datta J. Amiodarone-induced pulmonary toxicity - a frequently missed complication. Clinical Medicine Insights Case Reports. 2016;9:91-4. 
11. Musteikiene G, Miliauskas S, Zaveckiene J, Zemaitis M, Vitkauskiene A. Factors associated with sputum culture conversion in patients with pulmonary tuberculosis. Medicina (Kaunas). 2017;53(6):386-93.

12. Cruciani M, Scarparo C, Malena M, Bosco O, Serpelloni G, Mengoli C. Metaanalysis of BACTEC MGIT 960 and BACTEC 460 TB, with or without solid media, for detection of mycobacteria. J Clin Microbiol. 2004;42(5):2321-5.

13. Ohshimo S, Guzman J, Costabel U, Bonella F. Differential diagnosis of granulomatous lung disease: clues and pitfalls. Eur Respir Rev. 2017;26:170012.

14. Bonniaud P, Georges M, Favrolt N, Camus P. Drug-induced interstitial lung diseases. Rev Prat. 2014 Sep;64(7):951-6.

15. Vasic N, Pesut D, Stevic R, Jovanovic D, Radivojevic S. Amiodarone pulmonary toxicity: case report. Srp Arh Celok Lek. 2014 Jul-Aug;142(7-8):480-3.

16. Seki S, Itagaki S, Kobayashi M, Hirano T, Iseki K. Amiodarone increases the accumulation of DEA in a human alveolar epithelium-derived cell line. Biol Pharm Bull. 2008 Jul:31(7):1449-52.

17. Cho I, Mori S, Imamura F, et al. Methotrexate pneumonia lacking dyspnea and radiographic interstitial patterns during treatment for early rheumatoid arthritis: bronchoalveolar lavage and transbronchial lung biopsy in a differential diagnosis. Mod Rheumatol. 2007;17:256-61.

18. Keng L, Liao M. Amiodarone-induced hepatic and pulmonary toxicity. Postgraduate Medical Journal Published Online First. 2018. https://doi. org/10.1136/postgradmedj-2018-135779.

19. Mukhopadhyay S, Gal AA. Granulomatous lung disease: an approach to the differential diagnosis. Arch Pathol Lab Med. 2010;134:667-90.

Ready to submit your research? Choose BMC and benefit from:

- fast, convenient online submission

- thorough peer review by experienced researchers in your field

- rapid publication on acceptance

- support for research data, including large and complex data types

- gold Open Access which fosters wider collaboration and increased citations

- maximum visibility for your research: over $100 \mathrm{M}$ website views per year

At BMC, research is always in progress.

Learn more biomedcentral.com/submissions 